\title{
Individually assessed creep food consumption by suckled piglets : influence on post-weaning food intake characteristics and indicators of gut structure and hind-gut fermentation
}

\author{
E. M. A. M. Bruininx ${ }^{1}$, A. B. Schellingerhout ${ }^{2}$, G. P. Binnendijk ${ }^{1}$, C. M. C. van der Peet-Schwering ${ }^{1}$ \\ J. W. Schrama ${ }^{3}$, L. A. den Hartog ${ }^{4}$, H. Everts ${ }^{2}$ and A. C. Beynen ${ }^{2}$ \\ ${ }^{1}$ Animal Sciences Group, Wageningen UR, Research Institute for Animal Husbandry BV, 8203 AD Lelystad, The \\ Netherlands \\ ${ }^{2}$ Utrecht University, Faculty of Veterinary Medicine, Department of Nutrition, 3508 TD Utrecht, The Netherlands \\ ${ }^{3}$ Wageningen University, Department of Animal Science, 6700 AH Wageningen, The Netherlands \\ ${ }^{4}$ Nutreco Agriculture Research and Development, 5830 AE Boxmeer, The Netherlands
}

\begin{abstract}
+ Present address : CCL BV, Division of Research and Development, PO Box 107, 5460 AC, Veghel, The Netherlands. E-mail : erik.bruininx@ccl.nl
\end{abstract}

\begin{abstract}
Individual food intake characteristics and indicators of gut physiology of group-housed weanling pigs were measured in relation to pre-weaning consumption of creep food. Additionally, the effects of creep food consumption on pre-weaning body weight and gain were assessed. A total of 48 litters was used in two trials. From 11 days of age until weaning (day 28), all 48 litters were given a creep food (12.7 MJ net energy (NE) per $\mathrm{kg}, 15.2 \mathrm{~g}$ lysine per $\mathrm{kg}$ ) supplemented with $10 \mathrm{~g}$ chromium III oxide per $\mathrm{kg}$. Piglets showing green-coloured faeces on three sampling days were designated as good eaters, whereas piglets that never showed green faeces were labelled as non-eaters. Piglets having green faeces once or twice were designated as moderate eaters. Based on availability, body weight, litter origin, genotype and gender 29 good eaters, 32 moderate eaters and 29 non-eaters were selected in the first trial. In the second trial there were 30 good eaters, 33 moderate eaters, and 27 non-eaters. In each trial eight piglets of each creep-food eating type were immediately killed to serve as a reference group. The remaining piglets of each eating type were weaned and placed in pens equipped with computerized feeding stations so that distributions of body weight, litter origin, and gender were similar within pens. In each trial, eight pigs of each eating type were killed 5 days after weaning in order to determine villous heights and crypt depths in the proximal small intestine and volatile fatty acid (VFA) concentrations in the colon. While being suckled, body weight was not related to the preweaning consumption of creep food ( $\mathrm{P}>0 \cdot 1)$ whereas average daily gain of the good eaters during the creep feeding period was higher $(\mathrm{P}<0.05)$ than that of the moderate and non-eaters. Both morphology measures and VFA concentrations on the day of weaning were unaffected ( $\mathrm{P}>0 \cdot 1)$ by the pre-weaning food consumption. After weaning, food intake and gain of the total group of good eaters were higher $(\mathrm{P}<0.05)$ than that of the non-eaters, whereas villous height and villous height: crypt depth ratios did not differ $(\mathrm{P}>0.1)$. Neither total VFA concentration nor the proportion of branched-chain VFA were affected by creep food consumption while being suckled. Total VFA concentration in the colon was positively associated with body-weight gain $(\mathrm{P}<0 \cdot 001)$. This study confirms earlier findings that consumption of creep food while being suckled stimulates food intake and growth after weaning. However, the beneficial effects were not associated with a prevention of damage to morphology of the small intestine.
\end{abstract}

Keywords: creep feeding, food intake, pigs, small intestine, weaning. 


\section{Introduction}

The weaning of pigs at an early age (3 to 4 weeks) is associated with dramatic changes (e.g. villous atrophy, crypt hyperplasia) in the structure of the small intestine (Hampson, 1986; Kelly et al., 1991). The changes in gut integrity are generally associated with poor performance as they are considered to temporarily decrease the digestive and absorptive capacity of the small intestine (Pluske et al., 1995). The impaired digestion causes considerable amounts of undigested nutrients to enter the hind gut where they act as a substrate for bacterial fermentation, resulting in increased levels of volatile fatty acids (Makkink, 1993; van Beers-Schreurs, 1996). A portion of the volatile fatty acids originates from the fermentation of undigested dietary protein (Rasmussen et al., 1988; Houdijk, 1998) while protein fermentation in young pigs is negatively associated with performance (Fukuyasu and Oshida, 1986; Houdijk, 1998). A continuous supply of nutrients to the gut after weaning is considered to prevent the detrimental changes in gut structure and function after weaning (Kelly et al., 1991; Pluske et al., 1996a and $b$ ). Thus, food consumption immediately after weaning is considered essential for both performance and gut function of piglets.

In practice, piglets being suckled are frequently offered a highly palatable diet (creep feeding) to supplement the piglets' nutrition due to decreasing milk production as lactation advances. Additionally, it may also stimulate food intake after weaning. Until recently, the effectiveness of creep feeding was unclear, mainly because pre-weaning food consumption varies greatly within and between litters, and because food intake after weaning also varies greatly among individual pigs. By using chromium III oxide as an indicator of individual preweaning food intake, and by using feeding stations to monitor individual food intake after weaning, we (Bruininx et al., 2002) have studied the relationship between pre- and post-weaning food intake and performance. We showed that the pre-weaning intake of solid food (creep food) stimulates food intake and gain after weaning, and decreases the time between weaning and first food intake (latency time).

In light of the above mentioned, it can be hypothesized that the pre-weaning intake of solid food improves the small intestinal morphology of the weaned pig and also it's digestive and absorptive capacity so that less protein fermentation will occur in the hind gut. In the present study, the effects of pre-weaning food consumption on post-weaning food intake, small intestinal morphology, and volatile fatty acid concentration in the colon at 5 days after weaning were assessed. An additional objective was to assess the effects of creep food consumption on pre-weaning body weight and gain.

\section{Material and methods}

During the period in which piglets were suckled, 48 litters divided over two trials were used. From this initial population, 132 (66 per trial) piglets were weaned and moved to the nursery pens to be monitored for 5 days. At 5 days after weaning, 48 piglets (24 per trial) that already were selected at weaning, were killed to collect intestinal tissue and digesta samples. From the initial population of 48 litters, another 48 piglets ( 24 per trial) were killed just before weaning to serve as a reference group in order to compare weaned and unweaned individuals. Pre- and post-weaning treatments and designs are given below.

\section{Pre-weaning}

Animals and design. All 48 litters (536 piglets) divided over two trials originated from rotationally bred sows and Great Yorkshire terminal boars (GY-s). The rotational breeding system involved three breeds : Dutch Landrace (DL), Finnish Landrace (FL), and Great Yorkshire sow line (GY-z). Because all piglets originated from boars of a similar genotype, the sow line with the largest contribution to the genetics of the piglet was considered the major genotype (Bruininx et al., 2000). Earlier results (Bruininx et al., 2002) suggested that the small intestinal morphology and volatile fatty acid concentrations in the colon of the piglets with the DL genotype were at variance with those of the FL and GY-z genotype. Therefore, in the present study only litters with the FL and GY-z genotype were used. Thus, the 536 piglets consisted of 271 FL and 265 GY$\mathrm{z}$ genotypical animals. From 11 days of age until weaning at 28 days, all litters were offered free access to a commercial creep food diet $(13.7 \mathrm{~g} / \mathrm{kg}$ apparently ileal digestible lysine and 12.7 MJ net energy per $\mathrm{kg}$ diet) containing $10 \mathrm{~g}$ chromium III oxide per $\mathrm{kg}$. Creep food was provided in plastic creep feeders (MS Agripan, Schippers, Bladel, The Netherlands) that could be fixed onto the slats in the farrowing pens. To avoid spillage of creep food, the creep feeders were partitioned.

Piglets were housed with their dam in conventional farrowing crates. The farrowing rooms were maintained at $20^{\circ} \mathrm{C}$ in combination with floor heating at $30^{\circ} \mathrm{C}$. All piglets received an intramuscular Fe injection (200 mg Fe; Fe Dextran, AUV Cuijk) on day 2 after birth. Each piglet was individually identified by a number tattooed in the right ear. All piglets had unlimited access to water via nipple drinkers. On 18, 20, 22, 25 and 28 days of age, food intake per litter 
was determined by collecting and weighing the remaining food. On 18, 22, and 27 days of age, faecal samples from all piglets were taken using faecal loops (Barnett et al., 1989). The colour of each sample was visually determined immediately. A green colour of the faeces indicated that the piglet had eaten creep food (Barnett et al., 1989; Bruininx et al., 2002). Piglets that showed green coloured faeces at all three sampling moments were designated as good eaters. Piglets that once or twice had green faeces were designated as moderate eaters. Hence, piglets that never showed green coloured faeces were designated as non-eaters. At the end of the period in which they were suckled (day 28), 29 good eaters, 32 moderate eaters, and 29 non-eaters were selected in the first trial. In the second trial there were 30 good eaters, 33 moderate eaters, and 27 non-eaters. Selection was based on availability, body weight (BW), litter origin, gender, and major genotype. In each trial, eight pigs of each eating type were immediately killed to serve as a reference group with regard to measurements on intestinal tissue and digesta. The remaining piglets of each type of creep food consumption were weaned and moved to the nursery room. On the day of weaning, sows were removed from the piglets at approximately 09:00 $\mathrm{h}$.

\section{Post weaning}

Experimental design. The experiment was conducted as a split-plot design. Pen was the whole plot and pigs within pens were the subplots. At weaning, the selected piglets (average of 22 per eating type) within a trial were randomly assigned to six pens of 11 pigs. Pens contained pigs of one major genotype only, but males, females, littermates, good eaters, moderate eaters, and non-eaters were similarly represented within the pens. Weaning and transferring the pigs to the nursery rooms was completed at approximately $12: 00 \mathrm{~h}$.

Pigs were weighed at weaning (28 days of age) and 4 days thereafter. At 5 days after weaning (33 days of age), eight pigs per eating type were killed in each trial; these piglets were selected before weaning on the basis of BW, litter origin, and gender. The Animal Experiments Committee of the Faculty of Veterinary Medicine of Utrecht University had approved all experimental protocols.

Housing and feeding. The nursery pens $(2.65 \mathrm{~m} \times 1.5 \mathrm{~m})$ had fully slatted floors which consisted of $1.8-\mathrm{m}$ plastic slats and $0 \cdot 85-\mathrm{m}$ metal tribar slats. The pens were situated in a room with computer-controlled heating and mechanical ventilation systems. The room was illuminated with artificial light from 07:00 to 19:00 h. All pens were equipped with IVOG ${ }^{\circledR}$ feeding stations (Individually
VOluntary food intake in Group housing; Insentec BV, Marknesse, The Netherlands) fitted for weanling pigs as described by Bruininx et al. (2001a). Briefly, these feeding stations recorded feeder weight and time at the beginning and end of each visit to the feeder together with an electronic identification number of the pigs that was given by an ear tag. IVOG $^{\circledR}$ data were checked according to the method of Bruininx et al. (2001b). The development of food intake of individual pigs during the 1st days after weaning was computed using the method of Bruininx et al. (2001b). Two variables were computed, i.e. the interval $(\mathrm{h})$ between weaning and first food intake (latency time) and the amount of food consumed during the first $24 \mathrm{~h}$ after the first recorded food intake (initial food intake, $\mathrm{g} / \mathrm{kg} \mathrm{M}^{0.75}$ ). Pigs were given free access to food and water during the whole post-weaning period. Water was supplied via nipples. During the 5-day post-weaning period, a pelleted pre-starter diet (Table 1) was provided that contained no antibiotics. Organic acids and

Table 1 Composition of the pelleted diet after weaning (as fed)

\begin{tabular}{lr}
\hline \hline Ingredients & $\mathrm{g} / \mathrm{kg}$ \\
Barley & $300 \cdot 2$ \\
Wheat & $150 \cdot 0$ \\
Corn & $150 \cdot 0$ \\
Whey powder & $124 \cdot 0$ \\
Toasted soya beans & $90 \cdot 0$ \\
Extracted soya beans & $60 \cdot 0$ \\
Tapioca & $34 \cdot 5$ \\
Fish meal & $30 \cdot 0$ \\
Linseed expeller & $14 \cdot 0$ \\
Fatt & $12 \cdot 5$ \\
Molasses, sugar beet & $10 \cdot 0$ \\
Limestone & $1 \cdot 5$ \\
Phytase pre-mix (1000 phytase units per kg) & $0 \cdot 5$ \\
L-Lysine-HCl & $3 \cdot 0$ \\
DL-Methionine & $2 \cdot 9$ \\
L-Threonine & $6 \cdot 7$ \\
--Tryptophan & $5 \cdot 2$ \\
Vitamin and mineral pre-mix $\ddagger$ & $5 \cdot 0$ \\
Chemical analysis & \\
Dry matter & $888 \cdot 0$ \\
Crude protein & $176 \cdot 0$ \\
Crude fat & $48 \cdot 0$ \\
Crude fibre & $28 \cdot 0$ \\
Ash & $65 \cdot 0$ \\
Net energy (MJ/kg)§ & $9 \cdot 86$ \\
\hline \hline
\end{tabular}

+ Mixture of $750 \mathrm{~g}$ animal fat and $250 \mathrm{~g}$ vegetable oil per $\mathrm{kg}$. $\ddagger$ Provided the following nutrients ( $\mathrm{mg} / \mathrm{kg}$ diet): retinol 3.6; cholecalciferol 0.045; folic acid 0.3; cyanocobalamin 0.0175; pantothenic acid 10; $\alpha$-tocopherol 20 ; biotin 0.05 ; menadione dimethyl-pyrimidinol 0.5; niacin 20; riboflavin 3.5; choline 500; pyridoxine 1.5; thiamine 1 ; cobalt 0.15 (as $\mathrm{CoSO}_{4} \cdot 7 \mathrm{H}_{2} \mathrm{O}$ ); copper 15 (as $\mathrm{CuSO}_{4} \cdot 5 \mathrm{H}_{2} \mathrm{O}$ ); manganese 25 (as $\mathrm{MnO}_{2}$ ); iron 100 (as Fe $\mathrm{SO}_{4} \cdot 7 \mathrm{H}_{2} \mathrm{O}$ ); zinc 65 (as $\mathrm{ZnSO}_{4}$ ); iodine 0.45 (as $\mathrm{KI}$ ); selenium $0 \cdot 25$ (as $\mathrm{Na}_{2} \mathrm{SeO}_{3} \cdot 5 \mathrm{H}_{2} \mathrm{O}$ ).

$\S$ Calculated according to the Dutch feed tables (Centraal Veevoederbureau, 2000) 
pharmacological levels of copper and zinc were not included either.

\section{Sampling}

All selected pigs were weighed, pre-medicated with $0.5 \mathrm{ml}$ Stresnil per $\mathrm{kg}$ BW (Janssen Pharmaceutica, Beerse, Belgium), and anaesthetized with isoflurane, oxygen and nitrous oxide administered through a facemask. During anaesthesia, the abdomen was opened and the entire gastro-intestinal tract was removed. Afterwards, the piglets were killed by an intracardial injection of $10 \mathrm{ml}$ sodium pentobarbital (200 mg/ml; Vetimex Animal Health BV, Bladel, The Nethelands). For histological measurements one sample of approximately $2 \mathrm{~cm}$ was taken from the small intestine (SI) at $1 \mathrm{~m}$ posterior to the pylorus. Two samples of $2 \mathrm{~g}$ of the contents of the colon (flexura centralis) were taken in order to determine volatile fatty acid (VFA), and dry matter (DM) concentrations.

\section{Histology}

For histology measurements, the tissue samples of the proximal SI were rinsed in saline, pinned to a piece of dental wax, fixed in $10 \%$ phosphate-buffered formalin, and embedded in paraffin wax. From each of these samples, two sections (4 to $6 \mu \mathrm{m}$ ) were cut. Measurements of villous height and crypt depth in the mucosa samples of the proximal SI were performed in haematoxylin and eosin stained sections. Villous height and crypt depth were measured at $100 \times$ magnification by means of the TEA Image Manager System (Difa Measuring Systems B. V., Breda, The Netherlands). The height of a villus was taken as the distance from the crypt opening to the tip of the villus. Per section, the mean of 10 values was calculated and used for further analysis.

\section{Digesta}

One 2-g digesta sample was mixed with $0.2 \mathrm{ml}$ of sulphuric acid, $2 \mathrm{ml}$ of water, and centrifuged at $10000 \mathrm{~g}$. The supernatants were analysed for VFA (Schutte et al., 1992) with caproic acid as the internal standard. According to Rasmussen et al. (1988), isobutyric, valeric, and iso-valeric acids in digesta mainly originate from proteolytic activity. The three acids were combined as branched-chain VFA (bcVFA) and expressed as a percentage (mol/ $100 \mathrm{~mol}$ ) of the total VFA in the digesta, total VFA being the sum of the concentrations of acetic-, propionic-, butyric-, iso-butyric-, valeric-, and isovaleric acid. The second $2-\mathrm{g}$ sample from each piglet was used for the determination of the DM content by freeze-drying.

\section{Statistical analyses}

Data for the unweaned piglets were statistically analysed following a split-plot design. Litter was the whole plot and piglets within litters were subplots. The data were analysed with GLM procedures of Statistical Analysis Systems Institute (1994) according to the following model:

$$
\begin{gathered}
Y_{i j k l m n}=\mu+T_{i}+G_{j}+e_{1, i j k} \\
+S_{l}+F_{m}+\text { interaction }+e_{2, i j k l m n}
\end{gathered}
$$

where $Y_{i j k l m n}=$ a specific trait per animal; $\mu=$ overall mean; $T_{i}=$ fixed effect of trial $(i=1,2), G_{j}=$ fixed effect of major genotype $(j=1,2) ; \mathrm{e}_{1, i j k}=$ error term 1 , which represented the random effect of litter $k$ nested within trial $i$ and major genotype $j ; S_{l}=$ fixed effect of gender $(l=1,2) ; F_{m}=$ fixed effect of creep food consumption $(m=1,2,3) ; e_{2}, i j k=$ error term 2 , which represented the random effect of animal $m$ in trial $i$, in litter $k$. The effects of trial and major genotype were tested against error term 1. The effects of gender, creep food consumption and all interactions were tested against error term 2. All data on gut physiology were analysed without a random effect of litter.

After weaning, pens contained piglets of one major genotype, Great Yorkshire or Finnish Landrace. Data were analysed as for the pre-weaning data except that pen, rather than litter, was the whole plot and pigs within pen, rather than piglets within litters, were the subplots ( $k=$ pen rather than litter in the model). All data on gut physiology were analysed without a random effect of pen.

Effects were considered significant if $P<0.05$. In accordance with our earlier results (Bruininx et al., 2001b), preliminary analysis showed that all data except the time between the start of the experiment and first food intake (latency time) followed a normal distribution. Therefore, survival-like KaplanMeier curves (Kalbfleisch and Prentice, 1980) were constructed for latency time as affected by creep food consumption (good eaters $v$. moderate-eaters $v$. noneaters).

\section{Results}

Preliminary analysis showed that that there were no effects $(P>0.1)$ of major genotype on food intake characteristics, performance, and indicators of gut physiology. Therefore, only the effects of gender and creep food consumption will be presented.

Pre-weaning food consumption and growth

Consumption of creep food varied greatly between litters, ranging from 24 to $690 \mathrm{~g}$ per piglet from day 11 to weaning at day 28 . Average creep food intake 
Table 2 Growth performance of sucking pigs as affected by gender and creep food consumption

\begin{tabular}{|c|c|c|c|c|c|c|c|}
\hline & \multicolumn{2}{|c|}{ Gender } & \multirow[b]{2}{*}{ s.e. } & \multicolumn{3}{|c|}{ Creep food consumptiont } & \multirow[b]{2}{*}{ s.e. } \\
\hline & Male & Female & & Non-eater & Moderate eater & Good eater & \\
\hline No. of piglets & 168 & 191 & & 56 & 176 & 127 & \\
\hline \multicolumn{8}{|l|}{ Body weight (kg) } \\
\hline Birth $\ddagger$ & $1.45^{\mathrm{a}}$ & $1.35^{\mathrm{b}}$ & 0.020 & $1 \cdot 40$ & $1 \cdot 39$ & $1 \cdot 42$ & 0.025 \\
\hline Start of creep feeding & $3 \cdot 69^{\mathrm{a}}$ & $3 \cdot 54^{\mathrm{b}}$ & 0.054 & $3 \cdot 68$ & $3 \cdot 60$ & $3 \cdot 57$ & 0.069 \\
\hline Weaning & $8 \cdot 17$ & 7.95 & $0 \cdot 111$ & $8 \cdot 06$ & 7.94 & $8 \cdot 18$ & $0 \cdot 143$ \\
\hline \multicolumn{8}{|c|}{ Average daily gain (g/day) } \\
\hline day 0 to 11 & 212 & 207 & 3.9 & 203 & 209 & 216 & $5 \cdot 0$ \\
\hline day 11 to weaning & 263 & 259 & $4 \cdot 1$ & $257^{a}$ & $255^{\mathrm{a}}$ & $271^{\mathrm{b}}$ & $5 \cdot 2$ \\
\hline day 0 to weaning & 243 & 239 & $3 \cdot 7$ & 241 & 237 & 245 & $4 \cdot 7$ \\
\hline
\end{tabular}

a,b Within a row and within a main treatment comparison, means without a common superscript differ $(P<0 \cdot 05)$.

+ All piglets were given access to a creep food containing chromium III oxide from day 11 after birth until weaning (day 28). A green colour of the faeces due to the presence of chromium III oxide indicated that a pig had eaten creep food. Piglets that showed green faeces at all three sampling times were designated as good eaters. Piglets that showed green faeces once or twice were designated as moderate eaters. Piglets that never showed green faeces were designated as non-eaters.

$\ddagger$ Interaction between gender and creep food consumption significant $(P<0 \cdot 05)$.

over this period was $301 \mathrm{~g}$ per piglet (no. $=48$; s.d. $=151$ ). About $0 \cdot 65$ of the total creep food intake was consumed from 22 to 28 days of age. From all 536 creep-fed piglets, 127 piglets showed green faeces on all three sampling days (good eaters), 176 piglets showed green faeces once or twice (moderate eaters), whereas 56 piglets never showed green faeces (non-eaters; Table 2). The faeces of the remaining 177 piglets were at least once considered to be impossible to judge due to indistinguishable colours. Data of these pigs were not used in the analysis of pre-weaning performance. At birth and at day 11 the BWs of the male piglets were higher than those of the female piglets $(P<0.001$ and $P<0.05$ respectively). Gender affected neither BW at weaning nor pre-weaning growth $(P>0 \cdot 1$; Table 2). Additionally, there was an interaction between gender and eating type $(P<0.05)$ with regard to the body weight at birth. The birth weight of the male non-eaters of creep food $(1.52 \mathrm{~kg})$ was higher

Table 3 Growth performance and individual food intake characteristics of pigs during the first four days after weaning as affected by gender, and creep food consumption

\begin{tabular}{|c|c|c|c|c|c|c|c|}
\hline & \multicolumn{2}{|c|}{ Gender } & \multirow[b]{2}{*}{ s.e. } & \multicolumn{3}{|c|}{ Creep food consumptiont } & \multirow[b]{2}{*}{ s.e. } \\
\hline & Male & Female & & Non-eater & Moderate eater & Good eater & \\
\hline No. of pigs & 68 & 64 & & 40 & 49 & 43 & \\
\hline \multicolumn{8}{|l|}{ Average daily food intake } \\
\hline Average daily gain $(\mathrm{g})$ & $\begin{array}{r}102 \\
-4\end{array}$ & $\begin{array}{r}129 \\
-4\end{array}$ & $\begin{array}{r}0 \cdot 5 \\
12 \cdot 0\end{array}$ & $-34^{\mathrm{a}}$ & $2^{\mathrm{ab}}$ & $\begin{array}{r}134^{\mathrm{b}} \\
20^{\mathrm{b}}\end{array}$ & $\begin{array}{l}10 \cdot 0 \\
15 \cdot 0\end{array}$ \\
\hline \multicolumn{8}{|l|}{ Daily visits } \\
\hline Total number & $36 \cdot 8^{\mathrm{a}}$ & $43 \cdot 6^{\mathrm{b}}$ & $2 \cdot 34$ & $37 \cdot 7$ & 38.5 & $44 \cdot 4$ & 2.94 \\
\hline Visits with food intake & $7 \cdot 3$ & $8 \cdot 1$ & 0.43 & $6 \cdot 7^{a}$ & $7 \cdot 5^{\mathrm{ab}}$ & $8.9^{\mathrm{b}}$ & 0.54 \\
\hline Time per visit (s) & 71 & 63 & $3 \cdot 1$ & 66 & 70 & 66 & $3 \cdot 8$ \\
\hline \multicolumn{8}{|l|}{ Visits with food intake } \\
\hline Time per visit (s) & 218 & 197 & $10 \cdot 4$ & 215 & 215 & 193 & $13 \cdot 0$ \\
\hline Food intake per visit $(\mathrm{g})$ & $15^{\mathrm{a}}$ & $14^{\mathrm{b}}$ & $0 \cdot 6$ & 14 & 15 & 15 & 0.7 \\
\hline Rate of food intake (g/min) & n) 4.6 & $4 \cdot 6$ & $0 \cdot 19$ & $3.9^{\mathrm{a}}$ & $4 \cdot 7^{\mathrm{ab}}$ & $5 \cdot 0^{\mathrm{b}}$ & $0 \cdot 24$ \\
\hline \multicolumn{8}{|c|}{ Initial food } \\
\hline intake ( $\mathrm{g} / \mathrm{kg} \mathrm{M}^{0.75}$ per day) & $\ddagger 16 \cdot 8$ & $19 \cdot 5$ & $2 \cdot 17$ & $17 \cdot 2$ & $18 \cdot 1$ & $19 \cdot 2$ & $2 \cdot 72$ \\
\hline
\end{tabular}

a,b Within a row and within a main treatment comparison, means without a common superscript differ $(P<0 \cdot 05)$.

† See Table 2.

$\ddagger$ Initial food intake = amount of food consumed during the $24 \mathrm{~h}$ following the first visit with food intake to the feeding station. 
$(P<0.05)$ than that of the females that were labelled as moderate and non-eaters $(1.34$ and $1.28 \mathrm{~kg}$ respectively), but did not differ $(P>0 \cdot 1)$ from the remaining combinations of eating type and gender. None of the BWs on any other weighing day was related $(P>0 \cdot 1$; Table 2$)$ to the consumption of creep food. Nevertheless, the good eaters grew faster during the creep-feeding period (day 11 to day 28; $P<0.05)$ than both the moderate and non-eaters. Growth during both the pre-creep and the total period in which piglets were suckled was not related to creep food consumption $(P>0 \cdot 1$; Table 2$)$.

Post-weaning food intake characteristics and performance The pattern of the survival-like, Kaplan-Meier curves for the interval (h) between the start of the experiment and first food intake (latency time) was affected by neither gender $(P>0 \cdot 1)$ nor by creep food consumption $(P>0 \cdot 1)$. Average daily food intake and average daily gain (ADG) were not affected by gender $(P>0.1$; Table 3$)$. The total number of daily visits to the feeding stations, the duration of these visits, and the amount of food consumed during the visits with food intake differed between boars and gilts $(P<0.05, P<0.1$, and $P<0.05$ respectively). Male pigs visited the feeding stations less frequently (36.8 v. 43.6 daily visits) than the females, but each visit lasted on average $8 \mathrm{~s}$ longer, and the amount of food consumed during each successful visit was $1 \mathrm{~g}$ higher. The remaining food intake characteristics were not affected by gender $(P>0.1$; Table 3$)$. On a daily basis, both the number of visits with food intake and the rate of food intake during the successful visits of the good eaters were higher $(P<0.05$; Table 3$)$ than those of the non-eaters. These traits were intermediate for the moderate eaters. As a result, the pigs designated as good-eaters consumed more food and gained more during the first 4 days after weaning than the non-eaters, whereas ADFI and ADG of the moderate eaters were intermediate. Nevertheless, growth of all experimental groups was poor.

Morphology of the proximal small intestine before and after weaning

As expected, the unweaned piglets had villi that were on average $160 \mu \mathrm{m}$ longer $(P<0.001)$ and crypts $51 \mu \mathrm{m}$ less shallow $(P<0.001)$ than the piglets killed on day 5 after weaning. Consequently, the villous height to crypt depth ratio of the unweaned piglets was considerably higher than that of the weaned pigs $(2.3$ v. 1.2; $P<0.001)$. Gut architecture (villous height, crypt depth, and villous height to crypt depth ratios) was not affected by gender on either day 0 or day $5(P>0 \cdot 1$; Table 4$)$. Pre-weaning food consumption had no effect on gut architecture

Table 4 Morphology (villous height, crypt depth, villous/crypt ratios) of the proximal small intestine and the concentrations of total volatile fatty acids (Total VFA) and the percentage of branched-chain volatile fatty acids (bcVFA) in the colon at weaning and 5 days afterwards of piglets differing in gender, major genotype and pre-weaning food consumption

\begin{tabular}{|c|c|c|c|c|c|c|c|}
\hline & \multicolumn{2}{|c|}{ Gender } & \multirow[b]{2}{*}{ s.e. } & \multicolumn{3}{|c|}{ Creep food consumptiont } & \multirow[b]{2}{*}{ s.e. } \\
\hline & Male & Female & & Non-eater & Moderate eater & Good eater & \\
\hline \multicolumn{8}{|l|}{ At weaning } \\
\hline No. of piglets & 25 & 22 & & 16 & 16 & 15 & \\
\hline Villous height (mm) & 430 & 475 & $15 \cdot 5$ & 430 & 469 & 460 & $19 \cdot 0$ \\
\hline Crypt depth (mm) & 204 & 201 & $8 \cdot 8$ & 198 & 202 & 209 & $10 \cdot 8$ \\
\hline Villous height : crypt depth & $2 \cdot 2$ & $2 \cdot 4$ & $0 \cdot 13$ & $2 \cdot 2$ & $2 \cdot 4$ & $2 \cdot 3$ & $0 \cdot 15$ \\
\hline Total VFA (mmol $/ \mathrm{kg}$ digesta)f & $\ddagger 35.5$ & $30 \cdot 7$ & $5 \cdot 53$ & $25 \cdot 8$ & $39 \cdot 8$ & $33 \cdot 9$ & $6 \cdot 77$ \\
\hline bcVFA $(\%) \S$ & $6 \cdot 6$ & $6 \cdot 5$ & $0 \cdot 40$ & $6 \cdot 4$ & $6 \cdot 7$ & $6 \cdot 6$ & 0.48 \\
\hline Dry matter ( $\mathrm{g} / \mathrm{kg}$ digesta) & 234 & 218 & $11 \cdot 1$ & 220 & 233 & 224 & $13 \cdot 6$ \\
\hline \multicolumn{8}{|l|}{ At 5 days after weaning } \\
\hline No. of pigs & 26 & 22 & & 16 & 16 & 16 & \\
\hline Cumulative food intake $(\mathrm{g}) \|$ & 557 & 580 & $70 \cdot 1$ & 452 & 617 & 635 & 85.9 \\
\hline Cumulative gain $(\mathrm{g}) \|$ & 103 & 168 & $110 \cdot 8$ & 59 & 188 & 160 & $135 \cdot 7$ \\
\hline Villous height (mm) & 289 & 292 & $12 \cdot 4$ & 278 & 305 & 289 & $15 \cdot 2$ \\
\hline Crypt depth (mm) & 247 & 253 & $9 \cdot 3$ & 225 & 266 & 258 & $11 \cdot 4$ \\
\hline Villous height: crypt depth & $1 \cdot 2$ & $1 \cdot 2$ & 0.05 & $1 \cdot 3$ & $1 \cdot 1$ & $1 \cdot 1$ & 0.07 \\
\hline Total VFA (mmol $/ \mathrm{kg}$ digesta) & $\ddagger 78 \cdot 1$ & $81 \cdot 8$ & $6 \cdot 18$ & $73 \cdot 7$ & $87 \cdot 7$ & $78 \cdot 5$ & $7 \cdot 57$ \\
\hline bcVFA $(\%) \S$ & $4 \cdot 0$ & $4 \cdot 1$ & 0.51 & $4 \cdot 4$ & $4 \cdot 3$ & $3 \cdot 6$ & 0.63 \\
\hline Dry matter ( $\mathrm{g} / \mathrm{kg}$ digesta) & 136 & 136 & $14 \cdot 9$ & 132 & 148 & 129 & $15 \cdot 7$ \\
\hline
\end{tabular}

† See Table 2.

$\ddagger$ Total VFA = the sum of acetate, propionate, butyrate, iso-butyrate, valeric and iso-valeric acid.

$\S$ bcVFA = concentrations of branched-chain fatty acids being the sum of iso-butyrate, valeric and iso-valeric acid.

I| Cumulative food intake and gain were calculated from weaning until the moment of slaughter. 
either $(P>0.1$; Table 4) although there was a tendency towards an effect $(P=0.06)$ of creep food consumption on crypt depth on day 5 after weaning, . Crypts in the small intestine of the non-eaters were less deep than those of the moderate eaters, but did not differ from those of the good eaters (Table 4). Additionally, the cumulative food intake and gain from weaning until the moment of slaughter were also not affected by gender $(P>0 \cdot 1)$. Although cumulative food intake by the moderate and good eaters was proportionately about 0.4 higher than that of the non-eaters, this difference did not reach statistical significance $(P>0 \cdot 1$; Table 4$)$. The latter also applied for the differences in cumulative gain among the three eating types.

\section{Digesta characteristics}

The total VFA concentration in the colon contents of the unweaned piglets was lower than that in the piglets killed at day 5 post weaning (34.2 v. 81.2 $\mathrm{mmol} / \mathrm{kg}$ respectively; $P<0.001)$, but the percentage bcVFA in the unweaned piglets was higher $(6.6 \mathrm{v}$. $4.0 \%$ respectively; $P<0.001)$. The DM content of the digesta in the colon of the unweaned piglets was higher $(P<0.001)$ than in the weaned piglets (226 $v$. $133 \mathrm{~g} / \mathrm{kg}$ respectively). Digesta characteristics both before and 5 days after weaning, were affected neither by gender $(P>0.1)$ nor by creep food consumption $(P>0 \cdot 1$; Table 4$)$.

\section{Discussion}

Total litter creep food consumption varied greatly between litters, which is in line with several other studies (Okai et al., 1976; Barnett et al., 1989; Pajor et al., 1991; Bruininx et al., 2002). Considering the frequency of the occurrence of green faeces as an indicator of individual creep food consumption, there was also considerable within-litter variation in creep food intake, which agrees with our earlier results (Bruininx et al., 2002) and those of Pajor et al. (1991). Two mechanisms have been proposed that may explain the variation in pre-weaning food consumption among individual piglets. On the one hand some individual piglets may eat more creep food due to a more mature gastro-intestinal tract, which allows them to utilize nutrients from solids at an earlier age (Aumaitre, 1972). As large body size and rapid growth are likely to indicate greater developmental maturity, this mechanism would predict that the large piglets would eat more creep food (Pajor et al., 1991). Alternatively, it has been suggested that piglets may consume creep food to compensate for inadequate nutrition from milk (Algers et al., 1990), which implies that the smaller piglets would eat more creep food. The results of the present study do not support either mechanism since creep food consumption was not related to BW.
However, the piglets that had green faeces on all three sampling occasions had the highest ADG during the creep food period.

In accordance with Nabuurs (1991), who adopted the technique of temporary weaning to stimulate food intake during nursing, villous height in the small intestine of the unweaned piglets was not affected by the consumption of creep food. Nabuurs (1991) did find deeper crypts in the small intestine of the pigs that were offered creep food. In contrast, in this study, crypt depth in the small intestine of the unweaned piglets was not affected by creep food consumption. Because of a lower digestibility of the creep food compared with sows'milk, it was anticipated that the pre-weaning consumption of solids would result in an accumulation of undigested nutrients in the colon (Etheridge et al., 1984). VFA in the large intestine are end products of microbial fermentation, and their total concentration in the large intestine depends, among other factors, on the amount of available substrate (van Beers-Schreurs et al., 1998). Consequently, it was hypothesized that the VFA concentration in the colon of the piglets that ate creep food would be highest due to an increased fermentation activity of the microflora. Before weaning, the group-mean total VFA concentration of the good and moderate eaters of creep food was higher than that of the non-eating pigs, but the difference was not statistically significant. Thus it appears from this study that the consumption of creep food does not affect morphology of the small intestine nor the microbial activity in the colon during the period when the piglet is being suckled.

In accordance with our earlier results (Bruininx et al., 2002), the consumption of creep food during the preweaning period resulted in a higher ADFI and ADG during days 0 to 4 for the entire group of 43 pigs designated as good eaters. However, in contrast with our earlier results, there was no significant difference in latency time among the three experimental groups differing in creep food consumption $(P>0 \cdot 1)$. Nevertheless, the present results indicate that piglets consuming more dry food during lactation are better able to handle the dietary and social changes that occur at weaning as reflected by an increased postweaning food intake.

Although not statistically significant, the differences in cumulative food intake of the pigs that were selected for intestinal sampling reflected the differences in ADFI of the total population quite well. Thus it can be assumed that the data on the intestinal physiology of the pigs selected of each eating type reflect that of the entire group. It is well established that the oral intake of food and its 
physical presence in the gut are necessary for structural and functional maintenance of the intestinal mucosa (luminal nutrition; Kelly et al., 1991; Pluske et al., 1996a and b). Therefore, it was anticipated that the pre-weaning consumption of solids would result in an increased food intake after weaning, which in turn would result in less damage to the intestinal structure at 5 days after weaning. However, the present results indicate that despite the increased food intake, villous height was not affected by creep food consumption. Thus it seems that the stimulatory effect of pre-weaning food intake on food intake after weaning is not sufficient to prevent the occurrence of villous atrophy, whereas it is beneficial for post-weaning gain. These results conflict with those of Nabuurs (1991), who concluded that supplementary feeding while being suckled resulted in villi that were longer 4 days after weaning than on the day of weaning. As stated above, those authors adopted the technique of temporary weaning to stimulate food intake during the suckling period. However, they did not report pre- and post-weaning food intake by the pigs, neither for individual pigs nor on a pen basis. In contrast to villous height, there was a tendency for crypt depth to be affected by the experimental treatments. Crypts of the moderate eaters were deeper $(P=0.06)$ than those of the non-eater whereas crypt depths of the good eaters were intermediate. It is known that the process of villous recovery gathers momentum at 5 to 8 days after weaning (Miller et al., 1986; Cera et al., 1988). Due to an increase in food intake after a starvation period early after weaning, the cell cycle time in the crypts decreases, resulting in an increase in the number of crypt cells which in turn results in deeper crypts (Goodlad and Wright, 1984). Theoretically, the deeper crypts of the moderate and good eaters may indicate the start of villous recovery. Indeed, compared with the non-eaters the good and moderate eaters had a higher cumulative food intake, which is in line with the deeper crypts of the latter two groups.

Although an effect of creep food intake on intestinal morphology was not found in the present study, ADG of the total group of pigs considered as good eaters was higher than that of the non-eaters, whilst ADG of the moderate eaters was intermediate. Thus, despite the lack of differences in intestinal morphology that reflected the differences in food intake, the good-eaters were able to utilize the extra food intake, as indicated by the increased ADG. It has been suggested by van Beers-Schreurs (1996) that the VFAs in the large intestine of weanling pigs may act as an energy source, which may compensate for an impaired digestive and absorptive function of the small intestine during the first days after weaning.
However, in the present study, the differences in VFA concentrations among the treatment groups were not statistically significant. Averaged over all experimental groups, about 0.35 of the variation $(P<0.001)$ in cumulative gain was explained by the variation in total VFA concentration in the colon. Additionally, 0.21 of the variation in total VFA concentration in the colon and 0.61 of the variation in cumulative gain were explained $(P<0.01$ and $P<0.001$ respectively) by the variation in cumulative food intake. It is possible that an increase in food intake during the first days after weaning results in an increase in the VFA concentration in the colon, which in turn, may be an important source of energy for the weanling pig. Alternatively, the relationship between VFA concentration in colonic digesta and weight gain is not of a cause-and-effect nature.

\section{References}

Algers, B., Jensen, P. and Steinwall, L. 1990. Behaviour and weight changes at weaning and regrouping of pigs in relation to teat quality. Applied Animal Behaviour Science 26: 143-155.

Aumaitre, A. 1972. Development of enzyme activity in the digestive tract of the suckling pig: nutrition significance and implications for weaning. World Review of Animal Production 8: 54-68.

Barnett, K. L., Kornegay, E. T., Risley, C. R., Lindemann, M. D. and Schurig, G. G. 1989. Characterization of creep feed consumption and its subsequent effects on immune response, scouring index and performance of weanling pigs. Journal of Animal Science 67: 2698-2708.

Beers-Schreurs, H. M. G. van. 1996. The changes in the function of the large intestine of the weaned pig. $P h$. D. thesis, Utrecht University.

Beers-Schreurs, H. M. G. van, Nabuurs, M. J. A., Vellenga, L., Wensing, Th. and Breukink, H. J. 1998. Role of the large intestine in the pathogenesis of diarrhoea in weaned pigs. Journal of Nutrition 59: 696-703.

Bruininx, E. M. A. M., Binnendijk, G. P., Peet-Schwering, C. M. C. van der, Schrama, J. W., Hartog, L. A., Everts, H. den and Beynen, A. C. 2002. Effect of creep feed consumption on individual feed intake characteristics and performance of group housed weanling pigs. Journal of Animal Science 80: 1413-1418.

Bruininx, E. M. A. M., Peet-Schwering, C. M. C. van der, Schrama, J. W., Hartog, L. A. den, Everts, H. and Beynen, A. C. 2001a. The IVOG $^{\circledR}$ feeding station: a tool for monitoring the individual feed intake of group-housed weanling pigs. Journal of Animal Physiology and Animal Nutrition 85: 81-87.

Bruininx, E. M. A. M., Peet-Schwering, C. M. C. van der, Schrama, J. W., Vereijken, P. F. G., Vesseur, P. C., Everts, H., Hartog, L. A. den and Beynen, A. C. $2001 \mathrm{~b}$. Individually measured feed intake characteristics and growth performance of group-housed weanling pigs: effects of sex, initial body weight, and body weight distribution within groups. Journal of Animal Science 79: 301-308. 
Bruininx, E. M. A. M., Swinkels, J. W. G. M., Parmentier, H. K., Jetten, C. W. J., Gentry, J. L. and Schrama, J. W. 2000. Effects of an additional iron injection on growth and humoral immunity of weanling pigs. Livestock Production Science 67: 31-39.

Centraal Veevoederbureau. 2000. [Chemical composition, digestibility, and feeding value of feedstuffs. ] Veevoedertabel, Centraal Veevoederbureau, Lelystad, The Netherlands.

Cera, K. R., Mahan, D. C., Cross, R. F., Reinhart, G. A. and Whitmoyer, R. E. 1988. Effect of age, weaning and postweaning diet on small intestinal growth and jejunal morphology in young swine. Journal of Animal Science 66: 574-584.

Etheridge, R. D., Seerley, R. W. and Wyatt, R. D. 1984. The effect of diet on performance, digestibility, blood composition and intestinal microflora of weaned pigs. Journal of Animal Science 58: 1396-1402.

Fukuyasu, T. and Oshida, T. 1986. [Use of Neosugar in piglets.] Proceedings of the third Neosugar research conference, pp. 1-18.

Goodlad, R. A. and Wright, N. A. 1984. The effects of starvation and refeeding on intestinal cell proliferation in the mouse. Virchows Archiv 45: 63-73.

Hampson, D. J. 1986. Alterations in piglet small intestinal structure at weaning. Research in Veterinary Science 40: 32-40.

Houdijk, J. 1998. Effects of non-digestible oligosaccharides in young pig diets. Ph. D. thesis, Wageningen Agricultural University.

Kalbfleisch, J. D. and Prentice, R. L. 1980. The statistical analysis of failure time data. John Wiley and Sons, New York.

Kelly, D., Smyth, J. A. and McCracken, K. J. 1991. Digestive development in the early- weaned pig. 1. Effect of continuous nutrient supply on the development of the digestive tract and on changes in digestive enzyme activity during the first week post-weaning. British Journal of Nutrition 65: 169-180.

Makkink, C. A. 1993. Of pigs, dietary proteins, and pancreatic proteases. Ph. D. thesis, Wageningen Agricultural University.
Miller, B. G., James, P. S., Smith, M. W. and Bourne, F. J. 1986. Effect of weaning on the capacity of pig intestinal villi to digest and absorb nutrients. Journal of Agricultural Science, Cambridge 107: 579-589.

Nabuurs, M. J. A. 1991. Etiologic and pathogenic studies on postweaning diarrhoea. Ph. D. thesis, Utrecht University.

Okai, D. B., Aherne, F. X. and Hardin, E. T. 1976. Effect of creep and starter composition on feed intake and performance of young pigs. Canadian Journal of Animal Science 56: 573-586.

Pajor, E. A., Fraser, D. and Kramer, D. L. 1991. Consumption of solid food by suckling pigs: individual variation and relation to weight gain. Applied Animal Behaviour Science 32: 139-155.

Pluske, J. R., Williams, I. H. and Aherne, F. X. 1995. Nutrition of the neonatal pig. In The neonatal pig: development and survival (ed. M. A. Varley), pp. 187-235. CAB International, Wallingford.

Pluske, J. R., Williams, I. H. and Aherne, F. X. 1996a. Maintenance of villous height and crypt depth in piglets by providing continuous nutrition after weaning. Animal Science 62: 131-144.

Pluske, J. R., Williams, I. H. and Aherne, F. X. 1996b. Villous height and crypt depth in piglets in response to increases in the intake of cows' milk after weaning. Animal Science 62: 145-158.

Rasmussen, H. S., Holtug, K. and Mortensen, P. B. 1988. Degradation of amino acids to short-chain fatty acids in humans. An in vitro study. Scandinavian Journal of Gastroenterology 23: 178-182.

Schutte, J. B., Jong, J. de, Weerden, E. J. van, and Tamminga, S. 1992. Nutritional implications of L-arabinose in pigs. British Journal of Nutrition 68: 195-207.

Statistical Analysis Systems Institute. 1994. SAS/STAT ${ }^{\circledR}$ user's guide, release 6.12 edition. SAS Institute Inc., Cary, NC.

(Received 28 December 2002-Accepted 1 August 2003) 